The long hot days and warm nights of summer are hard to beat, although it is likely that the holidays will be spent this year in Old Blighty rather travelling to foreign shores. The Trimuvirate, like others, are going to have to be content with listening to sizzling sounds over this summer. Here are the best sounds from the current issue of Thorax.

\section{LISTEN TO YOUR HEART}

Swedish pop duo Roxette, Per Gessle and Maria Fredriksson, recorded this song in the summer of 1988 and possibly this provided the inspiration for Axson and colleagues (see page 807) to investigate the relationship between heart failure and heart failure medications on the risk of moderate-to-severe acute exacerbation of COPD. Using retrospective cohort data from 2006 to 2016, 86795 patients with COPD without evidence of HF $(n=60047)$, possible HF $(n=8476)$ and newly diagnosed HF $(n=2066)$ were recorded. Newly diagnosed $\mathrm{HF}$ and possible $\mathrm{HF}$ increased exacerbation risk as did use of all HF medications. As Roxette reported over 30 years ago, you should always listen to your heart, there's nothing else you can do.

\section{WHAT A WONDERFUL WORLD}

Louis Armstrong's song from 1967 is in the Grammy Hall of Fame. It provides uplifting references to a pollution free world of blue skies, white clouds, colourful rainbows, green trees and even red roses in bloom. This is some distance from the concerns raised today, in particular in China, with air pollution having a major impact on respiratory health. Dawei Cao and colleagues (see page 815) investigated the effects of ambient PM2.5 on hospital admissions, cost and length of stay for respiratory diseases in Shanxi Province. The authors demonstrated significant respiratory burden attributable to $\mathrm{PM}_{25}$ exposure with each $10 \mu \mathrm{g} / \mathrm{m}^{3}$ increase corresponding to $0.5 \%$ increase in respiratory hospitalisation with associated hospital stay and cost. Indeed, almost 10000 respiratory hospitalisations could be attributable to $\mathrm{PM}_{2,5}$ exposures. If we want to aspire to live in a wonderful world, we must have a global change in our approach to air pollution. Thank you Louis for the guidance.

\section{RUN}

You may not expect "sounds of the summer" from a band called "Snow Patrol" (hailing mostly from Northern Ireland). However, in the summer of 2008, the band opened their set at the "Live 8" festival with their hit song "Run". Many of us will go for a run when in need to a quick fix of exercise. But is exercise a substitute for airway clearance in cystic fibrosis (CF) and should exercise include forced expirations? In this month's journal (see page 763), Ward and colleagues present the findings of a systematic review of exercise as a substitute for airway clearance in CF (12 studies - all of less than 2 weeks). They find expectoration is easier and mucociliary clearance is increased during exercise. Forced expirations provide no added value. Snow Patrol's next big hit was "Chasing cars" - best not to attempt this when you next go for a run...

\section{SUNNY AFTERNOON}

When Ray Davies, of the Kinks, wrote "Sunny afternoon" he was not only singing the praises of lying in the sun drinking beer but also having a sly swipe at the powers of the state over the individual. "The tax man's taken all my dough, And left me in my stately home, Lazing on a sunny afternoon..." During the COVID-19 pandemic, the state has intervened in all our lives in ways that would not have seemed possible only a few years ago. But has it been worth it? In this issue, Qiu et al (see page 798) describe public health interventions designed to reduce COVID-19 cases in Hubei Province, China - where the pandemic began. The authors describe the effect of public health interventions (a travel ban and centralised treatment and isolation): the attack rate fell and doubling time was prolonged. This summer, travel bans will prevent many of us having an overseas holiday. Staycation may be the only option, still it could be worse: "Now I'm sitting here, Sipping at my ice cold beer, Lazing on a sunny afternoon".

\section{GIVE IT UP}

This classic by KC and the Sunshine Band was number one for 3 weeks exactly 38 years ago in August 1983. It is not originally written as a smoking cessation song, but if Mr Casey had read this paper by Huang and colleagues (see page 750) maybe he would have recognised the severe consequences of cigarette smoke and adapted the lyric a little. They showed that mice exposed to cigarette smoke have evidence of remodelled internal organs. This was associated with increased levels of IL33 (a distant relation of KC - I wonder if the Sunshine Band realised KC is in fact a potent chemokine) in Bronchoalveolar Lavage Fluid from COPD patients and cigarette smoke leading to fibroblast proliferation which was inhibited by blocking the IL33-ST2 axis. So maybe Keratinocyte Chemoattractant and the Sunshine tribute Band could encourage current smokers to 'give it up' this August. A fitting tribute.

\section{THE ONLY WAY IS UP}

If you fancy holidaying in Stornoway this summer I would recommend taking this summer classic with you. The outer Hebrides is famous for pristine beaches, single malt and crofting, a type of small holding. However, in Uganda smallholders are exposed to organophosphate and carbamate insecticides which may have adverse effects on lung function. To assess this Hansen and colleagues (see page 780) used haemoglobin-adjusted erythrocyte acetylcholinesterase to measure insecticide exposure and noted the correlation with low FEV1. It is apparent that if exposure to organophosphate and carbamates can be reduced then the only way is up for lung function.

\section{TAKE MY BREATH AWAY}

Old enough to remember "Top Gun"? If neither Tom Cruise or Kelly McGillis take your breath away, this month's teaser image may do (see page 848).

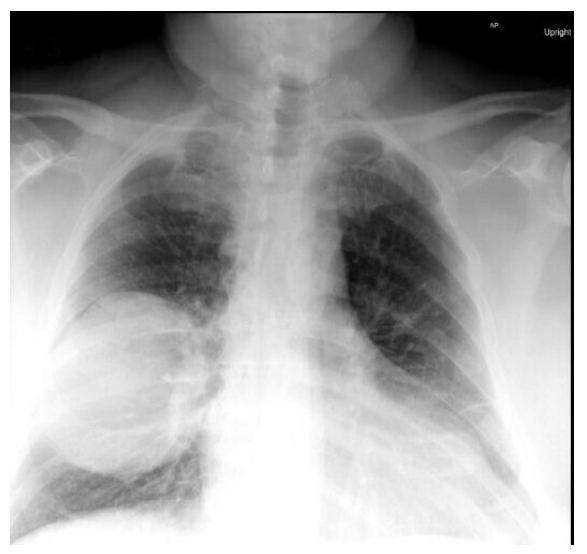

(C) Author(s) (or their employer(s)) 2021. No commercial re-use. See rights and permissions. Published by BMJ. 